\title{
Shock factor investigation in a 3-D finite element model under shock loading
}

\section{Abstract}

In this paper, a scaled 3D ship under shock loading is modeled and analyzed by finite element method. By using of shock factor, there is no need to have different tests or even numerical simulation. Shock factor is an important parameter which clarifies shock severity. It was found that although the new shock factor introduced by Yao et al. (2009), when constant, predict the response better than older shock factor, but for varying values of shock factors, the older would predict better. It is also found that costly and time-consuming experiments can be avoided by proper finite element modeling, yet the errors can remain within an acceptable range. The results of the present work can be used as benchmarks for future works.

\author{
Amin Zare*, a \\ Maziar Janghorban ${ }^{b}$ \\ ${ }^{a}$ Young Researchers Club, Shiraz Branch, Islamic \\ Azad University, Shiraz, Iran \\ Tel: +989178171427 \\ ${ }^{\mathrm{b}}$ Department of Mechanical Engineering, Shiraz \\ Branch, Islamic Azad University, Shiraz, Iran \\ Received 14 May 2012 \\ In revised form 16 Oct 2012 \\ *Author email: aminzare62@gmail.com
}

\section{Keywords}

underwater shock loading; shock factor; 3D finite element modeling.

\section{INTRODUCTION}

An explosion is a rapid release of energy, and can happen in the air, on the Earth's surface, underground or underwater [1]. Underwater explosions (UNDEX) occurring in the water near a ship hull are of great concern to surface ships and submarines since they can result in major hull damage. UNDEX is a very important and complex problem [2] and engages with a number of physical laws and properties, including the physical conditions at the boundaries of the explosive and the surrounding water [1].

The sequence of underwater explosion begins with the detonation of a high explosive. After the detonation, a shock wave travels through the charge material at a constant, high speed of approximately $7,620 \mathrm{~m} / \mathrm{s}$, converting the solid charge to a dense gas at great temperatures and pressures on the order of $3000{ }^{\circ} \mathrm{C}$ and 50,000 atm [2]. After detonation, a transient shock wave is produced and travels throughout fluid media. The peak pressure of this phase is very high, but its duration is extremely short. The second phase is a radial pulsation of the gas bubble as a result of its expansion and compression. Compared with the shock wave, this phase is characterized by lower peak pressure and much longer duration [3]. 
Shock wave, rather than bubble pulse, plays a dominant role for its intensity. On the contrast, if the stand-off is large enough, the effects of both shock wave and bubble pulse should be considered simultaneously. Typically, there is a gap between the arrival of the primary pulse and the gas bubble pulse. Therefore, they could be separately analyzed [4].

An alternative method for experimental and analytical ways to predict the effect of UNDEX on structures is to use similarity criteria. One of these methods is the "Shock Factor" (SF), which is a description of shock severity. Yao et al. also introduced a new SF based on energy acting on the structure [5]. He emphasized on the effectiveness of his new introduced SF in simulating the responses of a structure under shock loading, rather than former ones.

What is studied in this paper is the role of SF in predicting the response of a scaled ship model under shock loading, in addition to the effects of UNDEX loading on it, using the finite element (FE) software "ABAQUS". The present paper is organized as follows: In section 2 and 3, shock wave and shock factors are introduced. In section 4, the three-dimensional model of the ship is presented and finally, in part 5, the results are discussed and validated. At first, the results from the ship shock simulations are validated by the empirical formulations and results of Chen et al[3]. Then, the effects of shock loading are studied with SF constant and SF being varied.

\section{SHOCKWAVE}

During an underwater detonation of an explosive, the charge converts into a very hot and compressed gas and induces a shock wave migrating in the fluid media with a spherical shape and extremely short duration. The pressure of this shock at a given point has an instantaneous rise in time, followed by a decaying exponential fall [2]:

$$
P(t)=P_{\max } \exp \left(-\frac{t-t_{0}}{\theta}\right) \quad(M P a)
$$

where $P_{\max }, \theta$ and $t-t_{0}$ are the peak pressure of the shock wave (MPa), the time decay constant (ms) and the time elapsed after the arrival of the shock (ms), respectively. $P_{\max }$ and $\theta$ are expressed by the following formulations:

$$
\begin{gathered}
P_{\max }=K_{1}\left(W^{1 / 3} / R\right)^{A_{1}} \quad(\mathrm{MPa}) \\
\theta=K_{2} W^{1 / 3}\left(W^{1 / 3} / R\right)^{A_{2}} \quad(m \mathrm{sec})
\end{gathered}
$$

Where $R$ and $W$ are the radial stand-off distance from source to target $(\mathrm{m})$ and the mass of the explosive $(\mathrm{kg})$, respectively. $A_{1}, A_{2}, K_{1}$, and $K_{2}$ are constants depending on the explosive material as defined in Table 1.

Latin American Journal of Solids and Structures 10(2013) $941-952$ 
Table 1 Shock wave and bubble parameters [6]

\begin{tabular}{ccccc}
\hline Constants & $A_{1}$ & $A_{2}$ & $K_{1}$ & $K_{2}$ \\
\hline TNT & 1.18 & -0.185 & 52.12 & 0.092 \\
\hline
\end{tabular}

\section{SHOCK FACTOR}

The accurate theoretical research on UNDEX is difficult to execute due to its complexity and vast range of loadings (e.g., variations in charge weight, stand-off distance, and relative attack orientation), so model testing and numerical experiments become the main research methods. However, what is important is how to convert the results of model testing to real ship.

$\mathrm{SF}$ is a parameter that represents the severity of shock loading. High SF represents high energy impinged on a structure by an underwater shock. Thus, the response and excited damage of a structure can be estimated in terms of SF. Different types of shock factors have been introduced by different methods. In the first method, it is defined as [5]:

$$
C_{1}=\sqrt[3]{W} / R
$$

The other SF, defined by Yao et al.[5], was defined from the viewpoint of energy. They believe that an SF should be composed of charge weight, stand-off distance, structure geometry and also charge location. This new shock factor, defined on the assumption of spherical shock blast, can preferably reflect the underwater shock loading and can be used as similarity parameter in the analysis of the explosive environment. When it is constant, the time-history curves of the structural total kinetic energy and total potential energy are well alike, and the structural response of the average shock spectrum is generally identical. The formulation is

$$
C_{2}=\sqrt{4 \frac{W l}{\sqrt{4 R^{2}+l^{2}}} \arcsin \frac{r}{r+R}}
$$

Where $l$ and $r$ are cylinder length and radius, respectively (Figure 1).

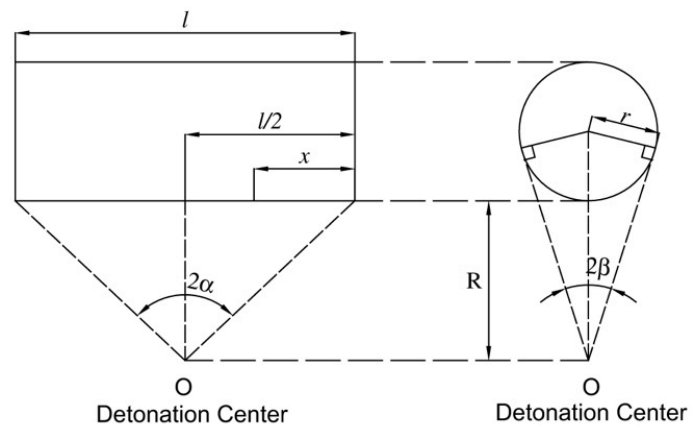

Figure 1 Loading geometry as demonstrated in [5] 


\section{BASIC MODEL}

A numerical study of structural responses to UNDEX consists of three parts: the structure, the surrounding fluid and the interaction between the fluid and the structure. The structure and surrounding medium can be modeled using the FE method. The interaction between structure and surrounding fluid was considered by $\mathrm{DAA}_{1}$ method [7].

The FE code ABAQUS was used for dynamic response analysis. The pre-processor of ABAQUS was used for three-dimensional mesh generation with the shell element for meshing the structure and the solid element for meshing surrounding water. Underwater shock loading was applied to the structure throughout the water around. The coupling between structure and water was simulated by the acoustic structure interaction method. The whole model is presented in Figure 2(a).

\subsection{Structure part}

What is modeled hereafter is a ship model, shown in Figure 2(b). The model has a basic structure, $13.2 \mathrm{~m}$ long slender box with rectangular section. The section is $0.8 \mathrm{~m}$ wide and $0.45 \mathrm{~m}$ high. 22 cabins divided along longitudinal direction ( $0.6 \mathrm{~m}$ in length for each cabin) by bulkhead or transverse frame were used. The cabins were ended by four watertight cabins, each of them has $3500 \mathrm{~kg}$ load capacity and two steel counter-weights (each weighting $85 \mathrm{~kg}$ ). The bottom and side plates were $8 \mathrm{~mm}$ and $5 \mathrm{~mm}$ in thickness, respectively. All frames were made from "L" sectioned angle steel. All the structure parts were meshed with 4-node shell element S4R [8] (Figure 3(a)).

\subsection{Fluid domain}

The infinite fluid domain was modeled and meshed using fluid 4-node AC3D4 acoustic tetrahedral elements in ABAQUS. The fluid elements were given the properties of water. The bulk modulus of water was specified using the formulation $\rho c^{2}$, where $\rho$ and $c$ stand for water density and sound velocity, respectively. The whole FE model of structure surrounded by the fluid is depicted in Figure 3(b).

\subsection{Boundary condition}

The ship model was floated on water freely; thus, there was no structural boundary condition (B.C.), but a fluid-solid interaction B.C. was considered between fluid and structural parts. The boundaries of the fluid may cause shockwave refraction or reflection. To prevent these phenomena, the external B.C. of the fluid element was set as a non-reflective impedance-type radiation boundary. The fact that the fluid is infinite was accommodated in the boundary conditions applied at the outer surface of the fluid.

Latin American Journal of Solids and Structures 10(2013) $941-952$ 


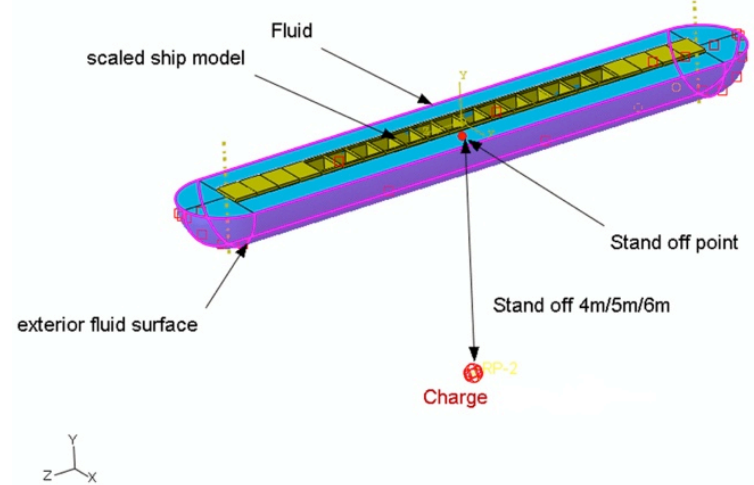

(a)

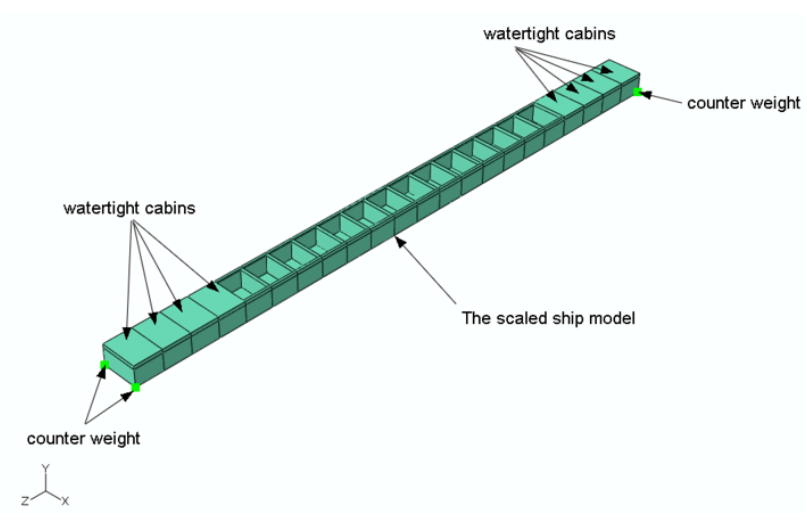

(b)

Figure 2 Scaled Ship models: a) Attack geometry surrounded by fluid media; b) Basic structure

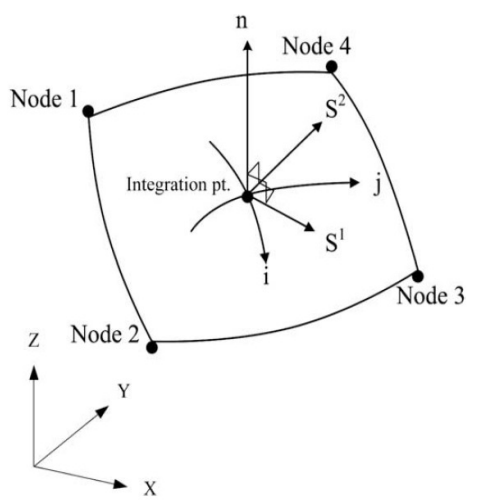

(a)

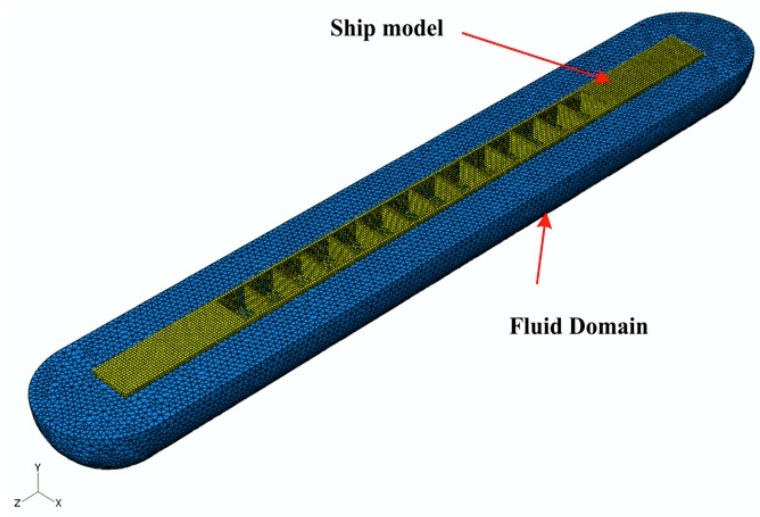

(b)

Figure 3 Finite element model a) 4-node shell element, S4R; b) FE model

\subsection{Model materials}

The material of structural model is high-strength steel and obeys Hooke's law. The parameters of steel and fluid environment (water) are Young's modulus 210 Gpa, Poisson's ratio 0.3, Mass density of structure $7850 \mathrm{~kg} / \mathrm{m}^{3}$, Mass density of water $1025 \mathrm{~kg} / \mathrm{m}^{3}$ and Underwater acoustic speed 1500 $\mathrm{m} / \mathrm{s}$.

\section{RESULTS AND DISCUSSION}

Results are presented in two sections. In the first section, the analysis results were validated by theory and experiment. These results are peak pressures, natural frequencies and related mode shapes, and finally the structure acceleration. The peak pressures were compared with theory and the others were compared with results of Chen et al.[3]. In the second section, the effects of various SFs were explored. 


\subsection{Validation of results}

Different loading conditions were applied by changing charge mass and stand-off distance. Charge masses of 0.5 and $1.0 \mathrm{~kg}$ and stand-off distances of 4,5 and $6 \mathrm{~m}$ were selected, which resulted in 6 different events, the same as the cases used in Chen et al.[3], (Table 2).

\subsubsection{Modal}

Modal frequencies were determined and related modes of ship model are plotted in Figure 4. As shown in Table 3, the results are in accordance with the results of Chen et al. [3]. The maximum error is 5.2\%; As a consequence, the constructed FE model simulates the real scaled ship well enough.

\subsubsection{Peak pressures and profile}

Pressure profile in the fluid domain, near the fluid structure interface, is shown in Figure 5. Taking a glance on the figure, one could see the radial-expanding behavior of shockwave that has migrated through fluid media and encounters the structure.

Good agreement between peak pressure in present study and theory was obtained (Table 2). The maximum error is $1.9 \%$ (the error increases by increase of stand-off distance and charge weight). It is concluded that shock loading simulation was done well. On the other hand, according to Table 2, peak pressure increases by increase of SF. Thus, SF could be considered as a criterion of underwater explosion severity.

Table 2 Loading events and resulted peak pressures

\begin{tabular}{|c|c|c|c|c|c|}
\hline \multirow{2}{*}{ Event number } & \multirow{2}{*}{$\begin{array}{l}\text { Charge weight } \\
(\mathrm{kg})\end{array}$} & \multirow{2}{*}{$\begin{array}{l}\text { Stand-off } \\
\text { distance }(\mathrm{m})\end{array}$} & \multicolumn{2}{|c|}{ Peak pressure (MPa) } & \multirow{2}{*}{$\begin{array}{l}\text { Error } \\
\% \\
\end{array}$} \\
\hline & & & Theory & Present study & \\
\hline 1 & 0.5 & 6 & 4.80 & 4.85 & 1.0 \\
\hline 2 & 0.5 & 5 & 5.94 & 6.03 & 1.5 \\
\hline 3 & 0.5 & 4 & 7.73 & 7.87 & 1.8 \\
\hline 4 & 1.0 & 6 & 6.29 & 6.39 & 1.6 \\
\hline 5 & 1.0 & 5 & 7.80 & 7.95 & 1.9 \\
\hline 6 & 1.0 & 4 & 10.15 & 10.32 & 1.7 \\
\hline
\end{tabular}

Table 3 Modal frequencies of scaled ship model

\begin{tabular}{|c|c|c|c|}
\hline \multirow{2}{*}{ Mode } & \multicolumn{2}{|c|}{ Frequency $(\mathrm{Hz})$} & \multirow{2}{*}{$\begin{array}{c}\text { Error } \\
\%\end{array}$} \\
\hline & ABAQUS & [3] & \\
\hline 1 & 6.1 & 5.8 & 5.2 \\
\hline 2 & 7.0 & 6.96 & 0.6 \\
\hline 3 & 16.5 & 16.1 & 2.5 \\
\hline 4 & 33.7 & 32.7 & 3.0 \\
\hline 5 & 28.9 & 28.2 & 2.5 \\
\hline
\end{tabular}

Latin American Journal of Solids and Structures 10(2013) $941-952$ 


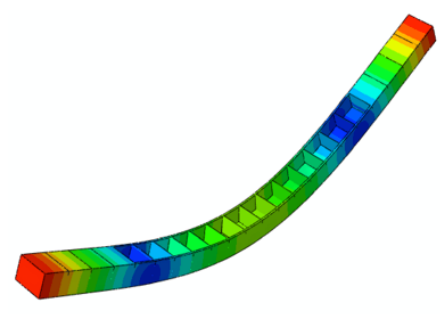

Mode 1

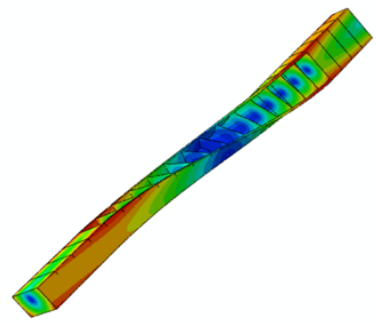

Mode 2

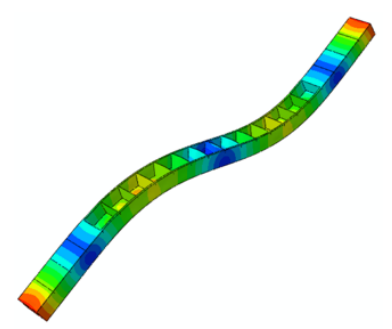

Mode 3

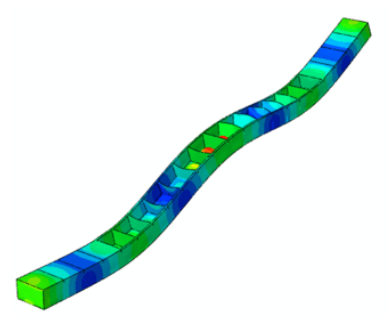

Mode 4

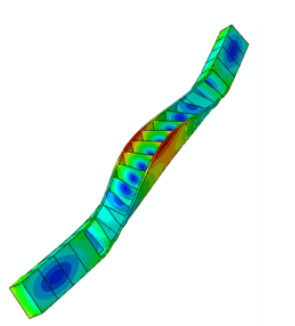

Mode 5

Figure 4 Mode shapes of scaled ship model

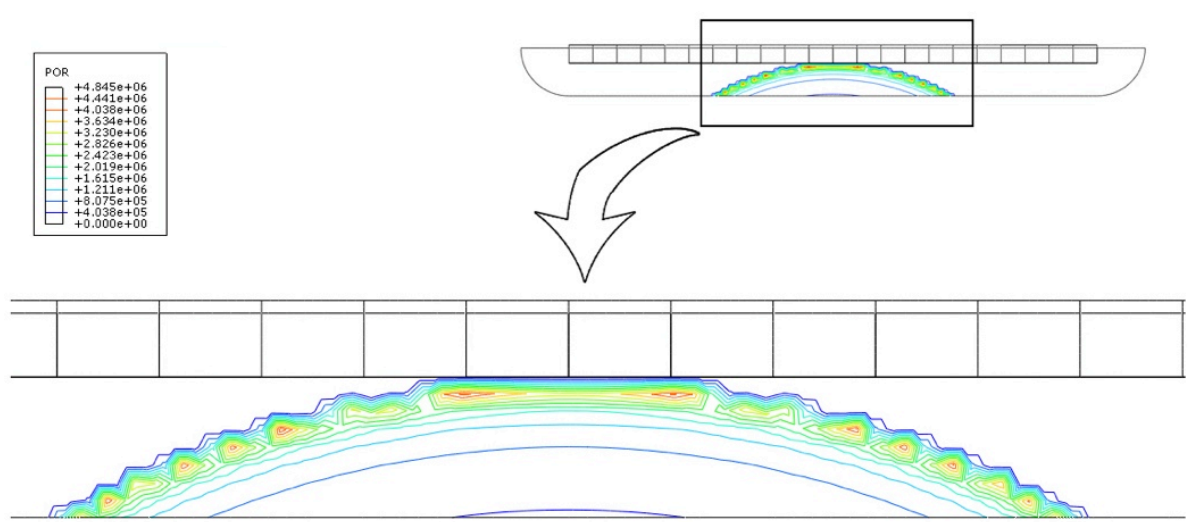

Figure 5 Pressure profile in the fluid domain, near the fluid-structure interface (for $0.5 \mathrm{~kg}$ TNT and stand-off $6 \mathrm{~m}$ )

\subsubsection{Acceleration}

One of the important criteria in ship design under shock loading is acceleration, because of its damage to the electrical utilities and other sensitive equipments. Hereafter, point $\mathrm{A}_{1}$ (Figure 6) was adopted on the structure surface. Its acceleration due to shot $(0.5 \mathrm{~kg}$ exactly under the structure at the stand-off of $6 \mathrm{~m}$ ) is plotted to show its severity (Figure 7). The peak acceleration value of point $\mathrm{A}_{1}$ is $3118 \mathrm{~g}\left(\mathrm{~g}=9.81 \mathrm{~m} / \mathrm{s}^{2}\right)$, which compares well with [3], 3137g (the error is $\left.0.6 \%\right)$.

In figure 7 , two peak values are seen. The first one belongs to shock wave pulse and the second one to the first bubble pulsation. 


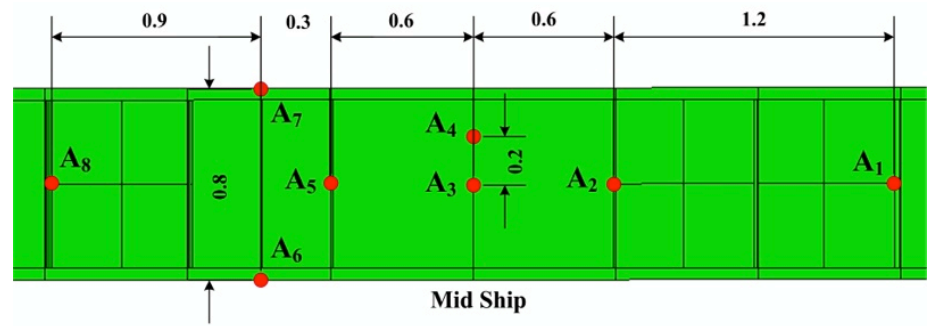

Figure 6 Points adopted on the structure bottom surface (all dimensions are in meter)

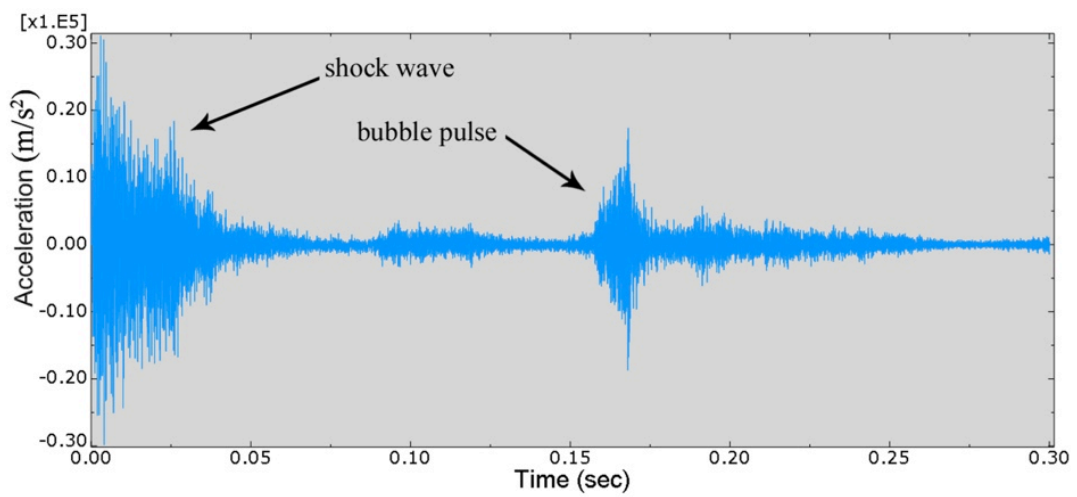

Figure 7 Acceleration of point $A_{1}(0.5 \mathrm{~kg}$ exactly under the structure at the stand-off of $6 \mathrm{~m})$

In this section, the model was checked in three sub-sections: modal analysis, shock loading effect and the resulting acceleration. It is concluded that the FE model is valid and can be used for shock factor investigation (discussed in the next sub-section), which is the further main aim of this paper.

\subsection{Shock factor investigation}

As explained before, a new shock factor was introduced by [5], which was an update form of the simple representation of $\mathrm{SF}\left(C_{1}\right)$. Different events, containing stand-off and charge weight, have been defined for a constant value of SF, for both $C_{1}$ and $C_{2}$, the same as the cases used in [5]. These cases can be found in Table 4 and Table 5 . The structure impact response was analyzed by the average spectrum velocity which is the arithmetical average of all adopted nodes (shown in Figure $6)$. The equation of average spectrum velocity is:

$$
V=\sum_{i}^{n} V_{i} \quad i=1, \ldots, 8
$$

Where $V$ is the average spectrum velocity, and $V_{i}$ is the velocity of the $i$ th node. 
The related average spectrum velocities (in direction $\mathrm{Y}$, according to Figure 2) for constant $C_{1}$ and $C_{2}$ (based on the points specified in Figure 6) are depicted in Figure 8. Though the shock factors corresponding to the curves in Figure 8(a) are almost alike, they still discrete severely. As shown in Figure 8(b), for constant shock factor $C_{2}$, average spectrum velocities collate well and only the shape of curves have slight difference. According to these results, it is concluded that "Shock factor $C_{2}$ preferably reflects the equivalency of underwater shock loading". In other words, for constant SFs, the differences between average spectrum velocities of $C_{1}$ are more than the ones of $C_{2}$.

Table 4 Events series defined for verification of $C_{1}$ [5]

\begin{tabular}{lllllll}
\hline$C_{1}=0.104$ & Case 1 & Case 2 & Case 3 & Case 4 & Case 5 & Case 6 \\
\hline Stand-off distance, $\mathrm{R}(\mathrm{m})$ & 9 & 12 & 15 & 18 & 24 & 30 \\
Charge weight, $\mathrm{W}(\mathrm{kg})$ & 0.81 & 1.92 & 3.75 & 6.48 & 15.36 & 30 \\
\hline
\end{tabular}

Table 5 Events series defined for verification of $C_{2}$ [5]

\begin{tabular}{lllllll}
\hline$C_{2}=2.149$ & Case 7 & Case 8 & Case 9 & Case 10 & Case 11 & Case 12 \\
\hline Stand-off distance, $\mathrm{R}(\mathrm{m})$ & 9 & 12 & 15 & 18 & 24 & 30 \\
Charge weight, $\mathrm{W}(\mathrm{kg})$ & 4.7 & 6.8 & 9.4 & 12.5 & 21.7 & 30 \\
\hline
\end{tabular}

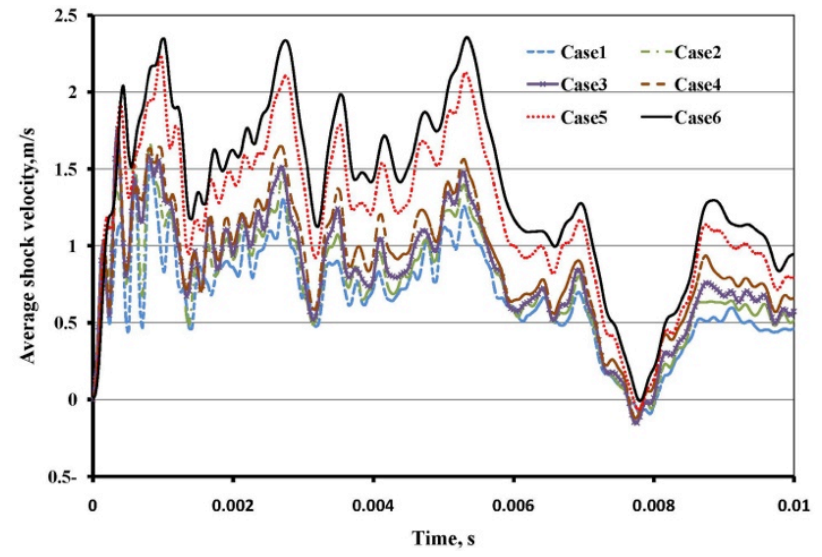

(a)

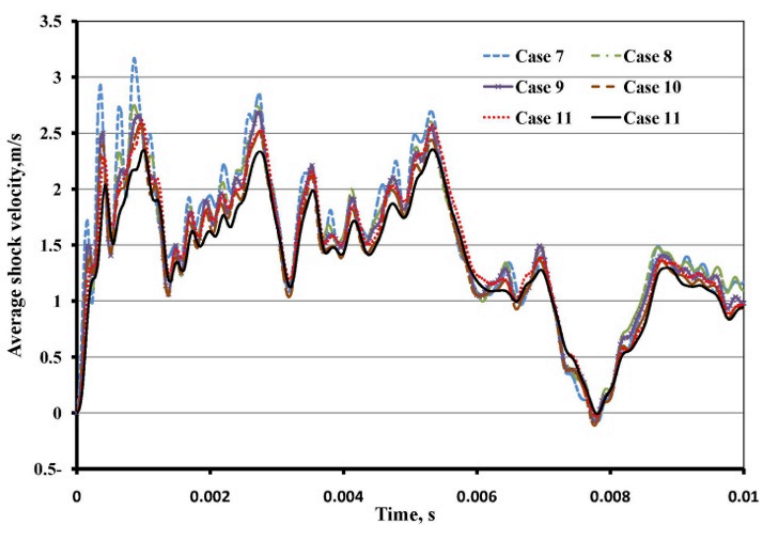

(b)

Figure 8 Average shock spectrum velocity for a) $C_{1}=0.104$; b) $C_{2}=2.149$

Another approach to investigate the effects of underwater shock loading on structural response is to define varying shock factor. In order to do so, different cases with various stand-off distances and charge weights were defined which produced different values for SFs (Table 6). For the cases described in Table 6, peak shock velocities were determined. In Figure 9, quotient of obtained values of $C_{1}, C_{2}$ and peak velocity to their first values (i.e. $\frac{C_{1}^{n}}{C_{1}^{13}}, \frac{C_{2}^{n}}{C_{2}^{13}}$ and $\left.\frac{\left(V_{\text {ave }}\right)^{n}}{\left(V_{\text {ave }}\right)^{13}} n=13, \ldots, 21\right)$ 
are shown. From the figure it is obvious that an increase in the ratio $\frac{C_{1}^{n}}{C_{1}^{13}}$ generates an approximated proportional increase in $\frac{\left(V_{\text {ave }}\right)^{n}}{\left(V_{\text {ave }}\right)^{13}}$, whereas an increase in $\frac{C_{2}^{n}}{C_{2}^{13}}$ don't hold this proportion and also the fraction values of $C_{1}$ are closer to peak shock velocity. As a result, $C_{1}$ would predict shock severity better than $C_{2}$ and if someone wants to use SF for predicting shock severity while it is varying, $C_{1}$ is a better choice than $C_{2}$.

Table 6 Events series defined to have varying SFs

\begin{tabular}{|c|c|c|c|c|c|c|c|c|c|}
\hline Events & $\begin{array}{l}\text { Case } \\
13\end{array}$ & $\begin{array}{l}\text { Case } \\
14\end{array}$ & $\begin{array}{l}\text { Case } \\
15\end{array}$ & $\begin{array}{l}\text { Case } \\
16\end{array}$ & $\begin{array}{l}\text { Case } \\
17\end{array}$ & $\begin{array}{l}\text { Case } \\
18\end{array}$ & $\begin{array}{l}\text { Case } \\
19\end{array}$ & $\begin{array}{l}\text { Case } \\
20\end{array}$ & $\begin{array}{l}\text { Case } \\
21\end{array}$ \\
\hline $\begin{array}{l}\text { Stand-off } \\
\text { distance, } \mathbf{R} \\
(\mathrm{m})\end{array}$ & 10 & 20 & 25 & 35 & 40 & 45 & 60 & 65 & 70 \\
\hline $\begin{array}{l}\text { Charge } \\
\text { weight, W } \\
(\mathrm{kg})\end{array}$ & 1.278 & 9.827 & 26.655 & 79.783 & 149.137 & 255.776 & 589.227 & 873.768 & 1249.37 \\
\hline$C_{1}$ & 0.4 & 0.6 & 0.8 & 1.0 & 1.2 & 1.4 & 1.6 & 1.8 & 2.0 \\
\hline$C_{2}$ & 0.113 & 0.157 & 0.207 & 0.255 & 0.305 & 0.355 & 0.405 & 0.455 & 0.505 \\
\hline
\end{tabular}

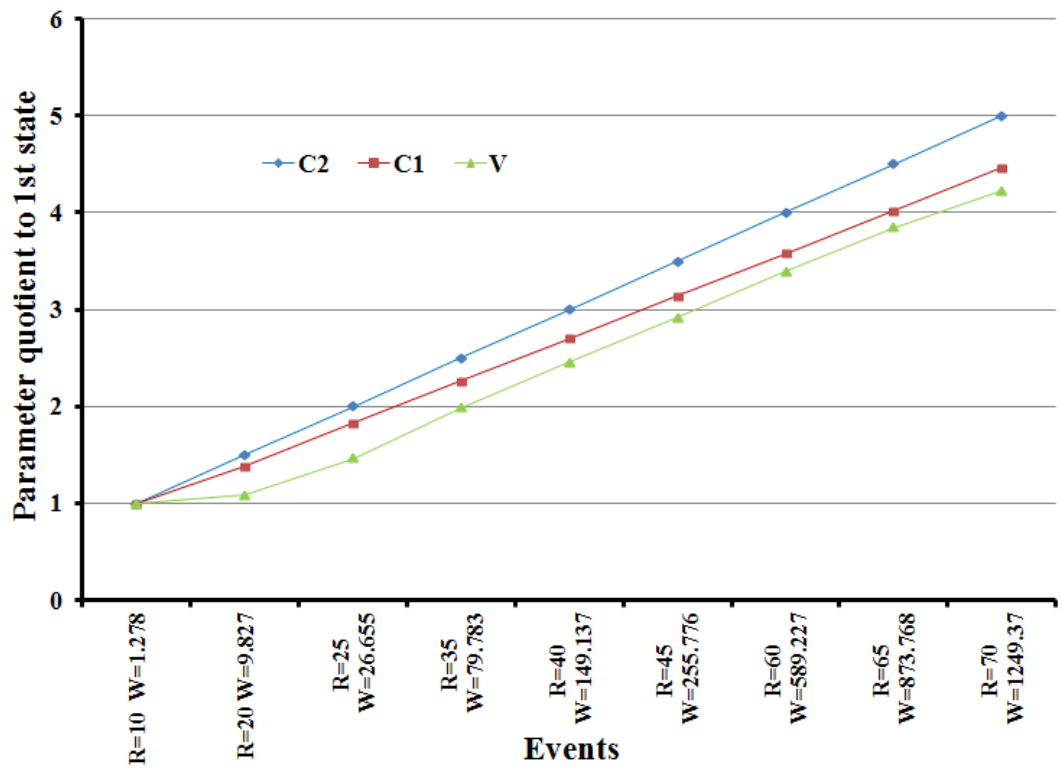

Figure 9 Average shock velocity, $C_{1}$ and $C_{2}$ 


\section{CONCLUSIONS}

In the present work, shock response was studied numerically on a scaled, 3D ship modeled by FE method subjected to underwater shock loading. Validation of the model was done with theory and experimental data in the literature. Results, such as peak pressure values, modal frequencies, mode shapes and acceleration, were compared and showed good agreement with theory and experiment. Also, the behavior of shock spectrum velocity was investigated. Conclusions are as follows:

1- Costly and time-consuming experiments could be avoided using a virtual environment (proper FE modeling), yet the errors can remain within an acceptable range.

2- Shock factor could be used as an important criterion in order to predict shock spectrum velocity (as a symbol of underwater shock loading). As a general rule, "the more the shock factor, the more the underwater shock loading".

3- For a constant shock factor (with different values of stand-off distance and charge weight), $C_{2}$ would estimate the response of the structure more accurate than $C_{1}$ (Figure 8).

4- For varying values of shock factor, $C_{1}$ would predict the response of structure better than $C_{2}$ (as shown in Figure 9).

\section{References}

[1] Bangash, M.Y.H. (2009). Shock, Impact and Explosion: Structural Analysis and Design. Springer.

[2] Cole, R. H. (1948). Underwater explosions. New Jersey: Princeton University Press.

[3] Chen, Y., Tong, Z.P., Hua, H.X., Wang, Y., Gou, H.Y. (2009). Experimental investigation on the dynamic response of scaled ship model with rubber sandwich coatings subjected to underwater explosion. Int. J. Impact Eng., Vol. 36, p. 318-328.

[4] Rajendran, R. (2009). Numerical simulation of response of plane plates subjected to uniform primary shock loading of non-contact underwater explosion. J. Materials and Design, Vol. 30, Issue 4, p. 1000-1007.

[5] Yao, X.-l., Guo, J., Feng, L.-h., Zhang, A-m. (2009). Comparability research on impulsive response of double stiffened cylindrical shells subjected to underwater explosion. Int. J. Impact Eng., Vol. 36, p. 754-762.

[6] Ucar, H. (2006). DYNAMIC RESPONSE OF A CATAMARAN-HULL SHIP SUBJECTED TO UNDERWATER EXPLOSIONS. Master's Thesis, Naval Postgraduate School, Monterey, California.

[7] Geers, T. L. (1978). Doubly Asymptotic Approximations for Transient Motions of Submerged Structures. J. Acoust. Soc. Am., Vol. 64, p. 1500-1508.

[8] Hibbitt, Karlsson and Sorensen,Inc., (2004). ABAQUS Analysis User's Manual.USA. 


\section{Appendix}

Some typical pressure contours of the model by different times are shown in Figure 10 to show the propagation of shock wave throughout the fluid domain near the structure.

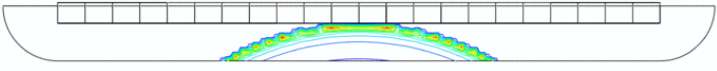

$\mathrm{t}=0.0 \mathrm{~ms}$

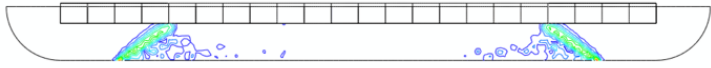

$\mathrm{t}=1.0 \mathrm{~ms}$

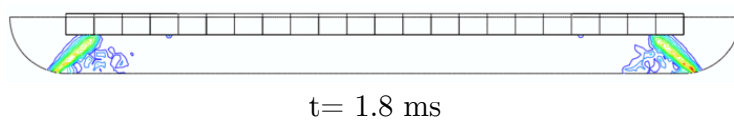

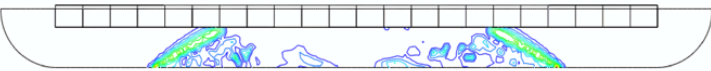

$\mathrm{t}=0.6 \mathrm{~ms}$

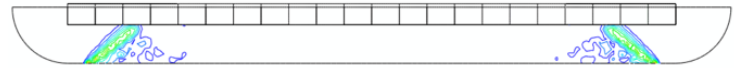

$\mathrm{t}=1.4 \mathrm{~ms}$

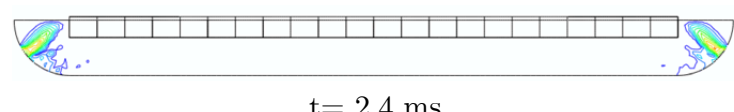

Figure 10 The propagation of shock wave 